\title{
HERÁLDICA DEL CONDADO: \\ SAN SALVADOR DE LEIRADO \\ Y SANTA MARÍA DE OLEIROS
}

\author{
Por \\ PLÁCIDO MÉNDEZ CRUCES
}

\section{RESUMEN}

Se trata de un estudio genealógico y heráldico de varias casas nobles existentes en las parroquias de San Salvador de Leirado y Santa María de Oleiros, pertenecientes al Ayuntamiento de Salvaterra de Miño, en el sur de la provincia de Pontevedra.

\section{PALABRAS CLAVE}

Escudos y generalogía en San Salvador de Leirado y Sta. María de Oleiros en Salvaterra.

\section{ABSTRACT}

Is question of a genealogyc and heraldry studio some noble houses to exist in the parish of St. Salvador de Leirado and Sta. María de Oleiros of Salvaterra de Miño in the south of the province of Pontevedra.

«CUADERNOS DE ESTUDIOS GALLEGOS», Tomo XLVIII, Fascículo 114, Santiago 2001. 


\section{KEYWORDS}

Genealogyc and heraldry St. Salvador de Leirado and Sta. María Oleiros, in Salvaterra - Pontevedra.

La Parroquia de San Salvador de Leirado, perteneciente al municipio de Salvaterra en la provincia de Pontevedra, es tierra de orígenes muy antiguos. En el lugar donde hoy se erige la Iglesia parroquial, según Ávila y La Cueva ${ }^{1}$ existió un monasterio de monjes Templarios; cuya denominación, como tal monasterio, todavía se usa en la Visita Pastoral de $1528^{2}$ que realiza el Visitador General Dr. Antonio de Cascante en nombre del Obispo D. Diego de Avellaneda, siendo Rector y Cura del mismo, Juan Rodríguez Nobás.

$\mathrm{Al}$ mismo tiempo también visita la Capilla de Nuestra Señora que estaba dentro del Monasterio, de la cual se describen sus bienes y rentas, siendo en esta época perteneciente al Obispo de Tui.

Esta capilla, que vemos dedicada a Ntra. Sra. de la Antigua, pasará a manos de los Sres. de Teans hacia 1592 en que aparece como fundador de la misma D. Fernando Ozores Sotomayor.

En el arreglo parroquial de 1854 se dice que formaba cuerpo con la iglesia, separada por el medianil del Norte, que estaba inútil y sin retablo destinada a guardar los enseres de la iglesia, y que contenía varias sepulturas de los antepasados de los Marqueses de Camarasa, Señores de Teans que decían ser sus propietarios y patronos.

Esta capilla fue derribaba al realizar la reconstrucción de la iglesia a principios del siglo XIX, la cual todavía podemos ver en los planos de la primitiva iglesia (Fig. 1). Procedente de esta capilla probablemente sean los escudos (Fig. 2) con las armas antiguas de los Ozores, actualmente empotrado en una de las paredes de la nueva casa rectoral. El otro (Fig. 3), depositado en el cementerio parroquial, lleva las armas de los Pallares de Portugal y Pereira de Castro, siendo visibles éstos últimos en otra parte del tempo.

\footnotetext{
${ }^{1}$ ÁVILA y LA CUEVA, Francisco. Historia Civil y Eclesiástica de la Ciudad de Tuy y su Obispado. Tomo V. Archivo de la Catedral de Tui.

${ }^{2}$ Libros de Visitas Pastorales, caxón 13, núm. 1. Archivo Histórico Diocesano de Tui-Vigo.
} 


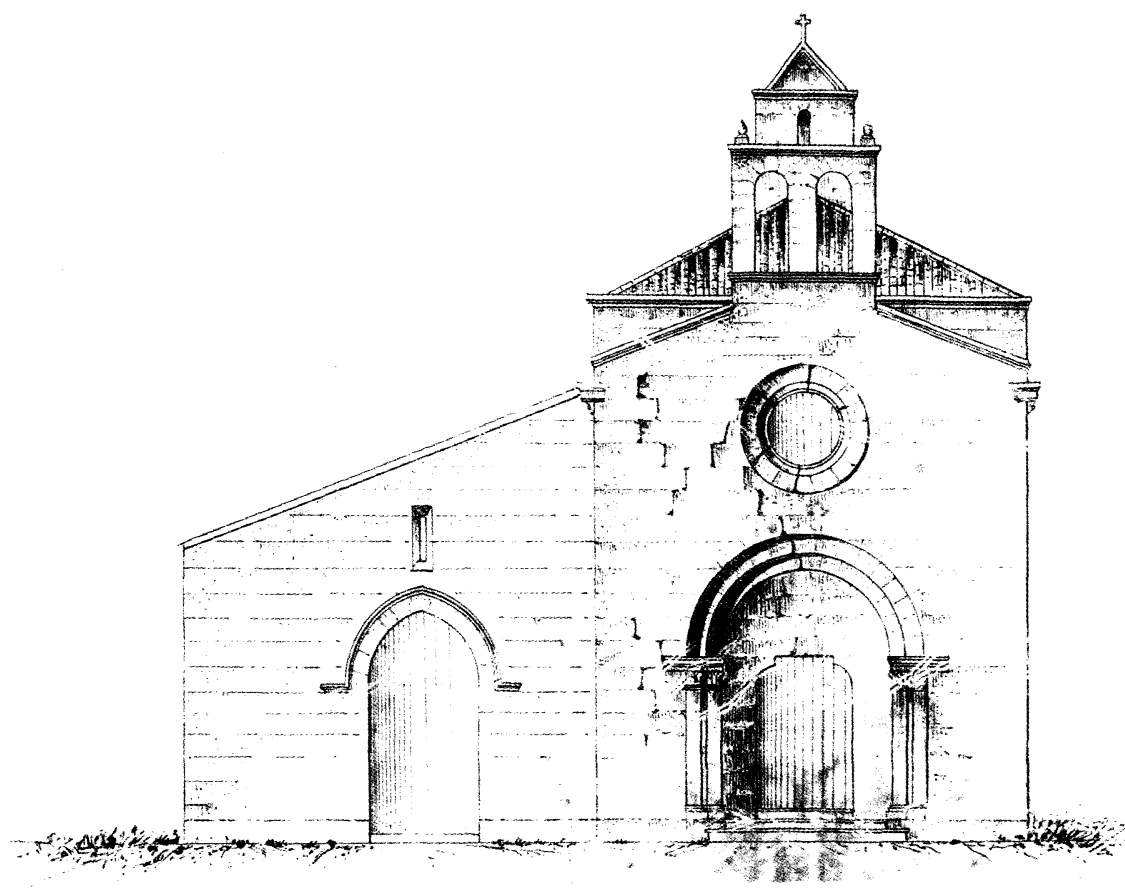

Fig. 1.

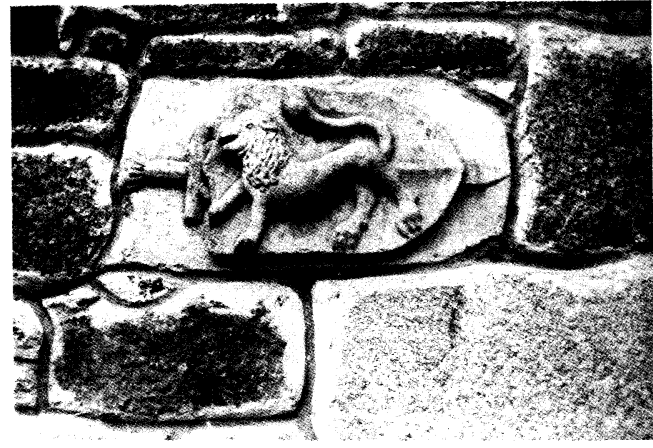

Fig. 2.

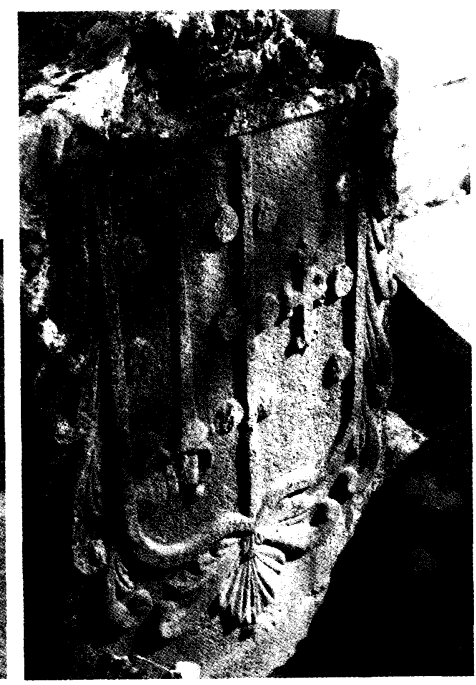

Fig. 3.

«CUADERNOS DE ESTUDIOS GALLEGOS», Tomo XLVIII, Fascículo 114, Santiago 2001. 
Al fallecimiento de D. Fernando Ozores, deja como patrono de la capilla a su hijo D. García Ozores II, y por dejación que había hecho su capellán, D, Pedro de Camba Ozores, presentado en 1617, por ser Abad de San Salvador de Maceira. El mismo D. García Ozores presenta como capellán al Bachiller D. Cristóbal Teixeira de Puga ${ }^{3}$.

En 1629 aparece como presentadora de la capilla Doña Inés de Camba Ozores, como tutora de su hijo mayor D. Fernando Ozores Señor de la Casa de Teans, presentando a D. Antonio Suárez de Puga como Capellán, siendo patrono de la misma el ya citado D. Fernando Ozores en 1641, presentando como capellán al Lic. D. Álvaro de Oya Benavides Ulloa, que luego hace dejación al ser nombrado Abad de Goián. Ya en 1648 aparece como Patrona Doña Constanza de Lemos y Acuña, mujer de Don Fernando residente en Madrid.

La presentación de esta capilla lo mismo que del beneficio curado de San Salvador de Leirado, como luego veremos, pertenecía por dos veces consecutivas a la Casa de Teans y luego una a la inmediata de Alcabra, que era del mismo origen de los Ozores.

Así vemos en $1721^{4}$ a D. Diego Sarmiento de Sotomaior Sotelo Prego de Montaos y Ozores, dueño de las jurisdicciones de Petán y Deva, de las Achas, etc. Señor de las Casas de Alcabra y Patrono insolidum del Convento de Ntra. Sra. de la Purificación de la villa de Redondela, como presentador de esta capilla, nombrando como capellán a D. Antonio Blanco de Puga, clérigo de menores, natural de Barcela y vecino de Valladolid por fallecimiento de D. Pedro Ventura Arias Conde y Ulloa, su último capellán.

En 1765 figura como patrono D. Francisco Miguel Gayoso Arcas Ozores López de Lemos, Conde de Amarante y Señor de la Casa de Teans, presenta a D. Carlos Reguera, clérigo de menores vec. de la Diócesis de Compostela ${ }^{5}$.

Ya en 1815 figura como tal Patrono D. Joaquín María Sarmiento de Mendoza, Marqués de Camarasa, residente en Madrid 6 .

La presentación del Beneficio curado de San Salvador de Leirado pertenecía, desde muy antiguo, a estas dos casas de los Ozores, la de Teans y

\footnotetext{
${ }^{3}$ Fondo Curia, caxón 32, núm. 3. A.H.D. de Tui-Vigo.

${ }^{4}$ Oficio Torre. Capellanías Ntra. Sra. la Mayor de Leirado 1721, A.C.T.

${ }^{5}$ Fondo Curia. Capellanías. Leirado 1765. A.H.D. de Tui-Vigo.

${ }^{6}$ Fondo Curia. Capellanías. Leirado 1815.
} 
Alcabra, siendo dicha presentación, lo mismo que en la Capilla de Ntra. Sra. de la Antigua, dos veces consecutivas por la casa de Teans y una por la de Alcabra.

De esta antigüedad nos hablan los escudos existentes en los contrafuertes exteriores de la capilla mayor (Figs. $4,5,6$ ) y el que figura en la clave de la bóveda (Fig. 7) que lleva en su exterior la inscripción latina de su lema «LA FORTUNA NO SABE ESTARSE QUIETA» o «ES VOLUBLE», con la representación del león de los Ozores con la espada fuera del campo, como representación arcaica de este apellido, que en este caso se remonta al año 1550 , fecha inscripta en una de las claves menores de la referida bóveda.

Ya en una época muy posterior, principios del siglo XIX, son las armas representadas en los extremos superiores del retablo mayor de la iglesia (Figs. 8 y 9): escudo partido, en campo de plata un león rampante de gules coronado de oro, una espada desnuda atravesando al león en banda, teniendo el león asida la guarnición de la espada con las garras, de los Ozores; tres fajas ajedrezadas de oro y gules en dos, tres y cuatro órdenes, separadas cada una con un ceñidor de plata, otros las traen de sable, de los Sotomayor. El otro escudo: en campo de plata una banda de sable, que toca con sus extremos los del escudo y por orla, una cadena de oro, de los Zúñiga. Ambos escudos se encuentran bajo una corona marquesal como ya pertenecientes a los Marqueses de Camarasa.

La primera noticia que hemos encontrado sobre estos presentadores data del 28 de octubre de 1592, en un testamento de Doña Isabel Ozores y Sotomayor, Sra. de la Fortaleza de Teans, la cual se manda enterrar a su fallecimiento en la Capilla Mayor, delante del altar donde se encontraba su hija Doña Francisca, bajo una piedra con sus armas, y que se le dijese una misa semanaria por su alma?

En 1721 aparece como presentador D. Andrés Gayoso Mendoza Ozores de Sotomayor, Señor de la Casa de Oca, Alférez Mayor de la ciudad de Ourense, marido de la Sra. Doña Constanza Arias Ozores, López de Lemos, Señora de las Casas de Ferreira y Sober, Amarante y Teans, Condesa de Amarante, Patrona in solidum de dos vacantes sobre tres del Beneficio de Leirado, residente en la ciudad de Santiago. Esta Dña. Cons-

\footnotetext{
${ }^{7}$ Fondo Curia, caxón 32, núm. 3. A.H.D. de Tui-Vigo.
} 


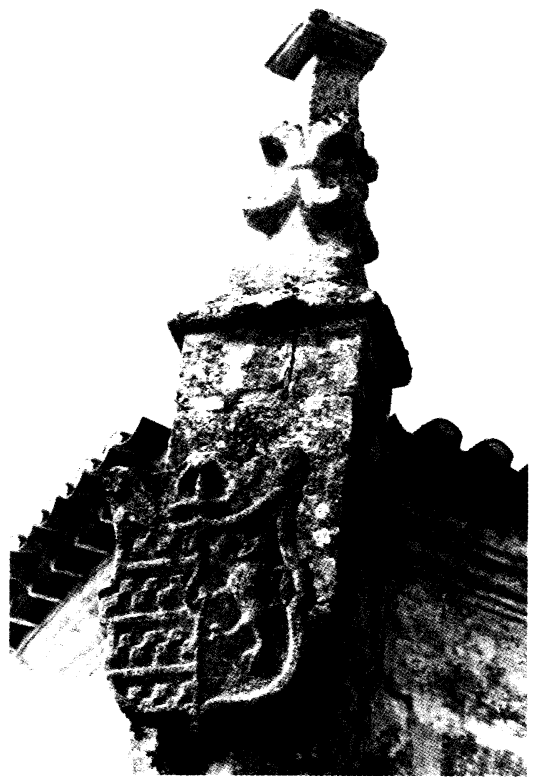

Fig. 4.

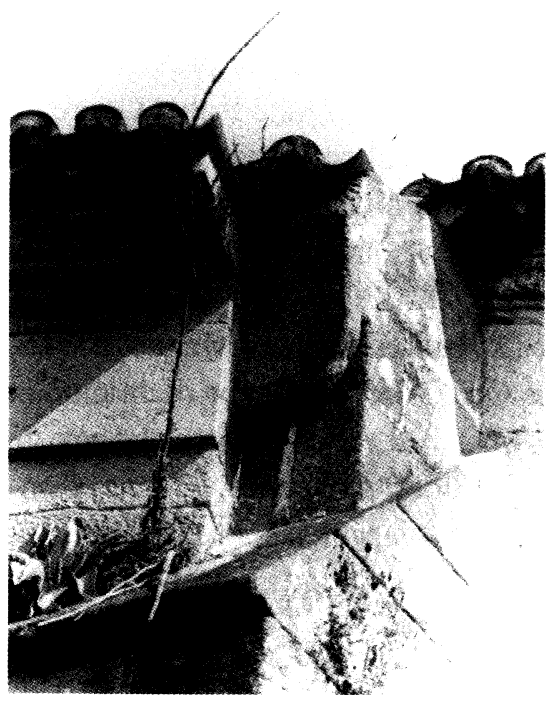

Fig. 6.

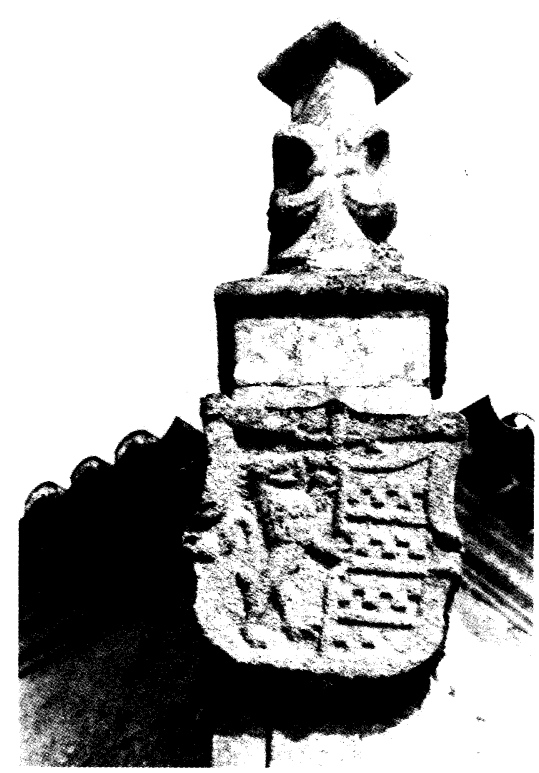

Fig. 5.

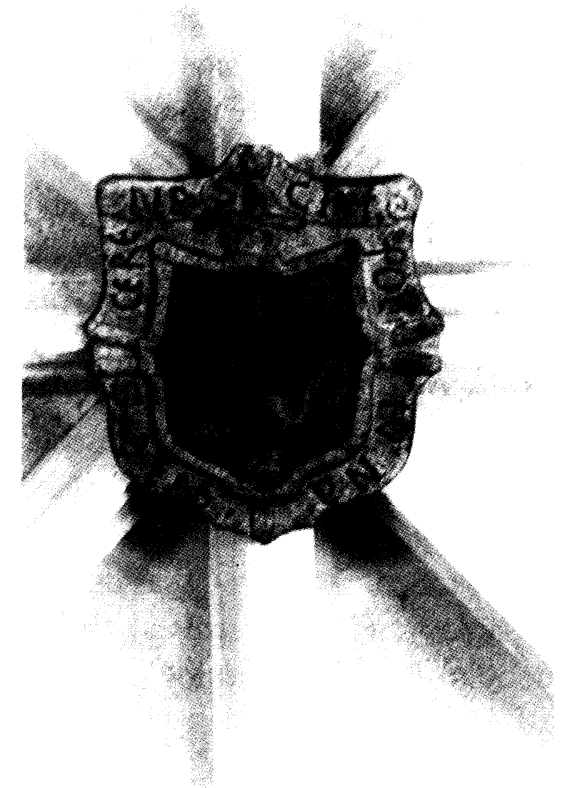

Fig. 7.

«CUADERNOS DE ESTUDIOS GALLEGOS», Tomo XLVIII, Fascículo 114, Santiago 2001. 


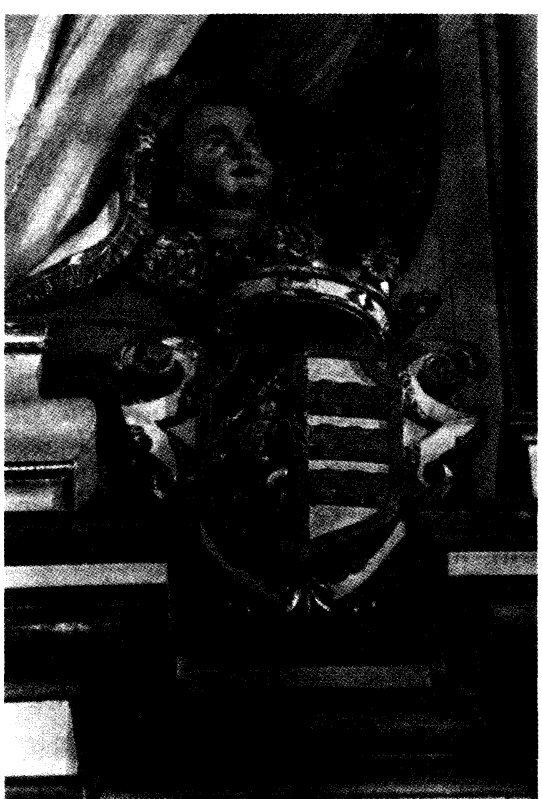

Fig. 8.

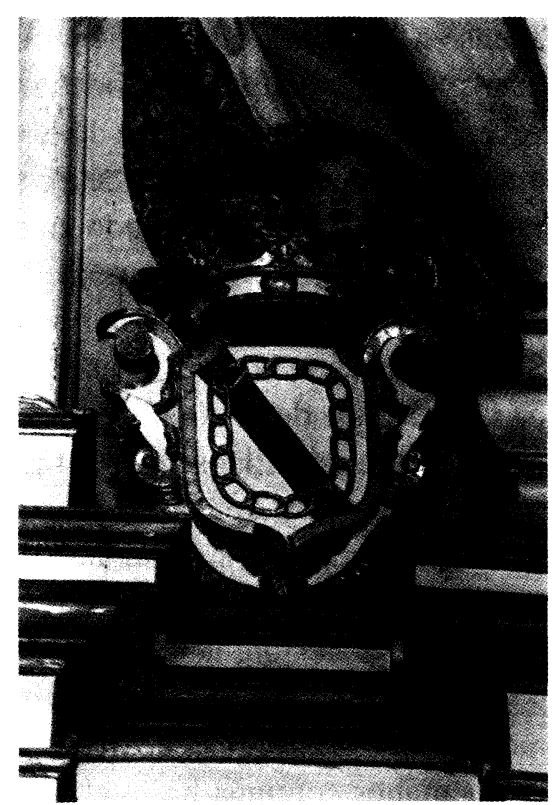

Fig. 9.

tanza, nacida en Lugo en 1669, había heredado esta casa de Teans de su hermano D. Pedro Arias Ozores, VI Conde de Amarante, fallecido sin sucesión.

En la vacante de 1776 aparece como presentador D. Domingo Francisco Miguel Gayoso Arias Ozores, Conde de Amarante, Alférez Mayor de Ourense y Regidor perpetuo de las ciudades de Ourense y Santiago.

En la vacante de 1844 aparece como presentador D. Joaquín María Gayoso Bermúdez de Castro, Sarmiento, Sotomayor, Arias, Ozores entre otros apellidos, Marqués de Camarasa, Conde de Amarante y Sr. de la casa de Teans.

\section{CASA DE TEANS}

Siguiendo al P. Crespo ${ }^{8}$ D. Vasco Ozores II c.c. Dña. Ana Paez de Sotomayor en 1496, serían los fundadores del vínculo de esta casa de

\footnotetext{
${ }^{8}$ CRESPO POZO. Blasones y Linajes de Galicia. Publicaciones del Monasterio de Poio.
} 
Teans en 1544 l.q.t.p.h. a D. García Ozores, que sería el primer Señor de Teans; D. Álvaro Ozores, fundador del Monasterio de las Benedictinas de A Guarda; D. Hernán Yáñez de Sotomayor, Sr. de la casa de Salcidos del que descienden los Condes de Priegue.

D. García Ozores I, casado en primeras nupcias con Dña. Aldonza de Sotomayor y t.p. a D. Fernando Ozores de Sotomayor, fundador de la Capelanía de Ntra. Sra. de la Antigua de Leirado y c.c. Dña. Antonia de Silva y Meneses, 1.q.t.p.h. a D. García Ozores II q.c.c. Dña. Inés de Camba Ozores, que de viuda ingresó como monja agustina en el Convento de Vista Alegre de Villagarcía, 1.q.t.p.h. a Fernando Ozores c.c. Dña. Constanza de Lemos y Acuña, hermana del $2^{\circ}$ Conde de Amarante y heredera del título al morir él mismo sin sucesión, los q.t.p.h. a D. García Ozores II, Conde de Amarante y Sr. de Teans, que c.c. Dña. Catalina Sarmiento y, al no tener sucesión, hereda su prima Dña. Juana Ozores.

Tal como hemos visto en la presentación del Beneficio curado de Leirado de 1844, esta casa de Teans pasa a los Marqueses de Camarasa en cuyas manos continúa hasta el año 1877 , en que aparece como propietario de la misma D. Alejandro Mon y Landa, vecino de Pontevedra.

\section{LA CASA DE TEANS}

Se hallaba situada en la parroquia de Oleiros, lindante con la de Salvaterra a cuyo municipio pertenece.

Poco o nada conserva de su primitiva arquitectura la actual casa de Teans, cuya reconstrucción debe datar de principios del siglo XIX.

Hoy tan solamente podemos admirar en sus jardines posteriores la artística capilla dedicada a Ntra. Sra. de la Concepción (Fig. 10), obra del famoso arquitecto Pedro de Monteagudo'. Fue edificada por D. García Ozores López de Lemos, Conde de Amarante en el año 1695, quién contrata con el referido arquitecto el 2 de Abril de 1695. Es precisamente sobre su portada que se encuentra el único escudo conservado en la casa (Fig. 11), en donde se puede apreciar el león de los Ozores.

${ }^{9}$ TAÍN GUZMÁN, Miguel. «La Capilla de Ntra. Sra. de la Concepción de Teans». Bol. Museo y Archivo Histórico Diocesano de Tui, T. VIII, fol. 245/52. Tui 1998.

«CUADERNOS DE ESTUDIOS GALLEGOS», Tomo XLVIII, Fascículo 114, Santiago 2001. 


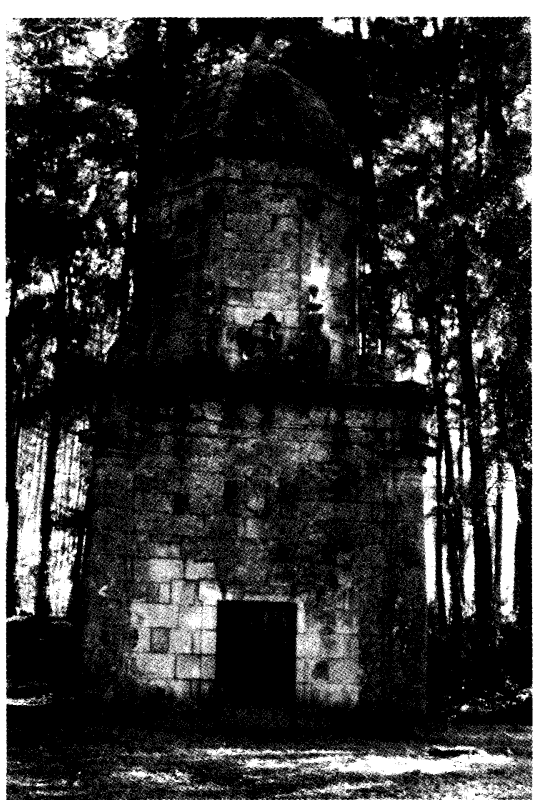

Fig. 10 .

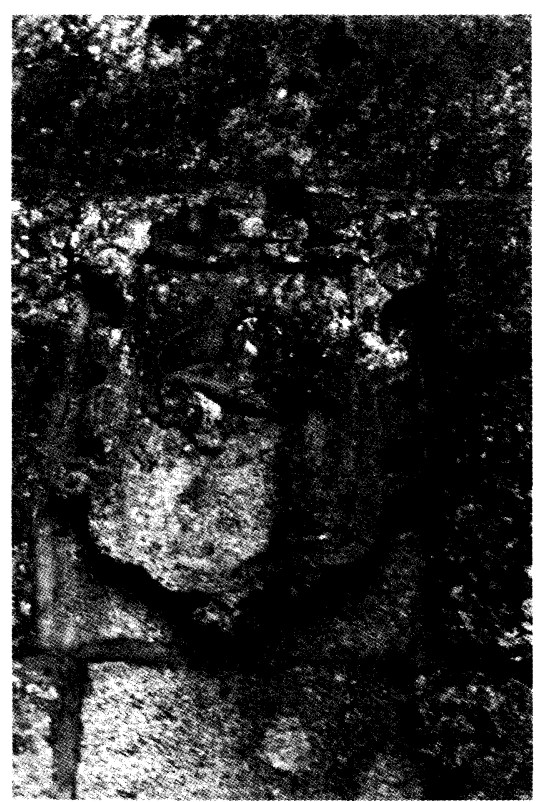

Fig. 11.

\section{LA CASA DE ALCABRA}

El Padre Crespo, en el apellido Ozores, nos propone otro árbol genealógico para la misma casa de Teans, que en realidad pertenece a esta de Alcabra que debía tener un mismo origen.

Esta casa de Alcabra, de la que no se conserva ningún resto, estaba situada en la misma parroquia de Oleiros, al extremo opuesto de la de Teans y hacia la orilla del río.

El primer personaje que nos propone el P. Crestpo es D. Fernando Yanes Ozores, Colegial mayor de Salamanca, Oidor y Regente en Sevilla, de la Orden de Alcántara, hijo segundo de esta casa de Teans que c.c. Dña. María Méndez y t.p.h. a D. Antonio Ozores de Sotomayor que nosotros vemos en 1598 , fundando una capilla dedicada a su santo patrono San Antonio junto a su casa de Alcabra ${ }^{10}$.

\footnotetext{
${ }^{10}$ Apeos, Tomo 77 (176), fol. 1. Archivo Catedral de Tui.
} 
D. Antonio Ozores c.c. Dña. Catalina de Vargas y Neira, hija de la Casa de Oca y t.p.h. a D. Fernando Ozores de Sotomayor, Administrador del Hospital Real de Santiago, el cual c.c. Dña. Isabel de Castro y Lamas de Carballedo, los q.t.p.h. a Diego Ozores, Administrador del Hospital de Santiago c.c. Dña. Isabel de Sequeiros, Condesa de Priegue.

Tal como hemos visto en la presentación de 1721 de la Capilla de Ntra. Sra. de la Antigua de Leirado esta casa pasa a D. Diego de Sotomayor, Sr. de Petán y Deva.

\section{MAYORAZGO DEL PAZO DE ARRIBA}

Se hallaba situado en la parroquia de Leirado. De esta casa solamente se conserva su portalón de entrada, en el cual se hallan flanqueando su puerta dos escudos de armas (Figs. 12 y 13), el primero con el apellido Muñoz, y el segundo con las armas de los Pereira de Castro, Sotomayor, Moscoso Ulloa, Troncoso de Lira Ozores. La casa ya en 1833 se hallaba completamente arruinada, sin techo y en muchas partes caída.

En 1833 D. Jacobo de Castro y Moscoso Somoza, pleiteaba con Juan Alonso Besada sobre el pago de desperfectos y entrega de papeles ${ }^{11}$.

Por fallecimiento de D. Francisco Pereira Moscoso, había recaído en la persona del citado D. Jacobo de Castro los vínculos y mayorazgos de Monterroso, en la parroquia de San Andrés de Cedeira; Pazo de Arriba, en esta de Leirado cuyo vínculo y mayorazgo había sido fundado por D. Juan de Soto Lobera y D. Francisco de Castro.

En el inventario de papeles de este mayorazgo, titulado de Leirado, se hace cargo en 1835 D. José Sarmiento Pereira, como poseedor del mismo al fallecer el citado D. Francisco Pereira Moscoso.

Unido a este mayorazgo de Leirado se encuentra también la llamada Casa de Peryra en la parroquia de San Fins de Nigrán ${ }^{12}$, tal como se deduce del inventario de papeles de este pleito, cuyo índice por su interés reproducimos:

\footnotetext{
${ }^{11}$ Pleitos. Fondo Hospital 1833. A.H.D. de Tui-Vigo.

${ }^{12}$ ESPINOSA, J. Casas y cosas del Valle Minor, pág. 87. Vigo, 1951.
} 


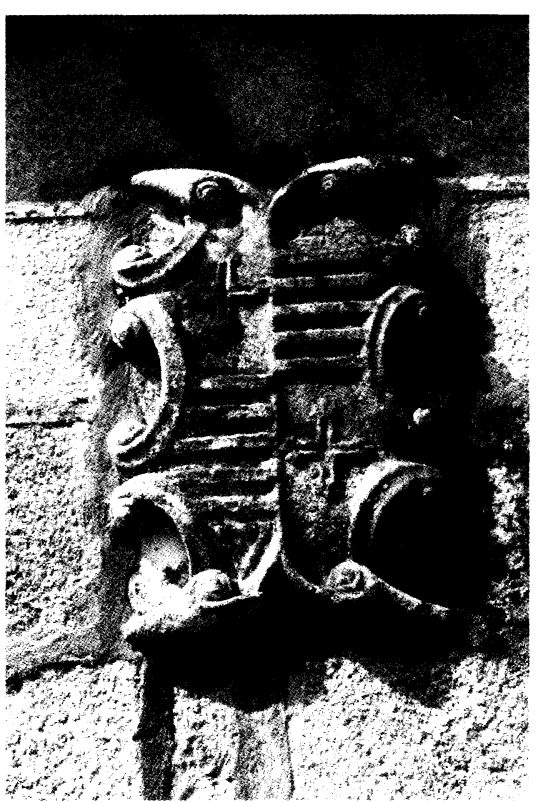

Fig. 12.

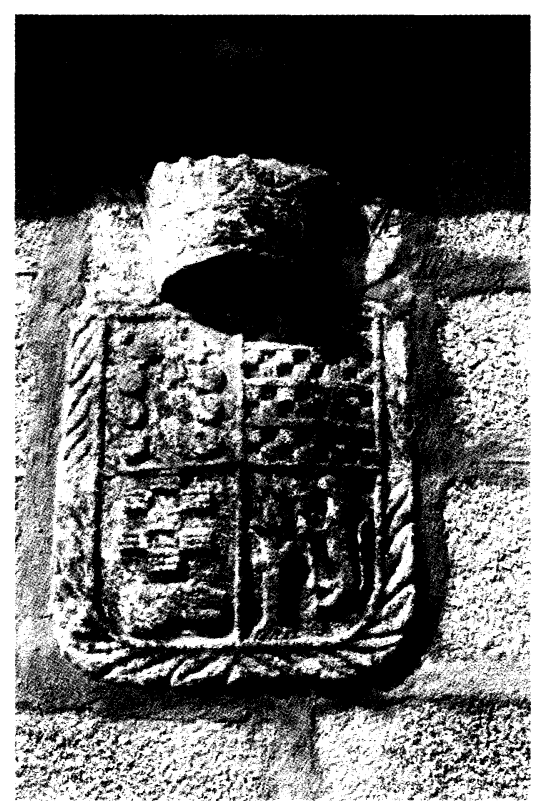

Fig. 13.

«Ejecutoria de Nigrán y Leirado 1729

- Real carta executoria titulada Sebastián Cortiñas y su mujer Dña. Manuela Pereira sobre paga de dote.

- Copia de la fundación de las casas de Nigrán y Leirado por el Capitán D. Manuel Pereira Andrade de Castro y Moscoso, y su mujer Dña. María Suárez de Araujo.

- Testimonio de Dña. María Josefa de Leyes Bermúdez contra D. Juan Antonio Patiño como marido de Dña. María Francisca de Arias y Saavedra, sobre los bienes de que hicieron vínculo D. Manuel Pereira y Dña. María Suárez de Araujo.

- Copia de escritura otorgada por Dña. María Ozores Correa y Sotomayor, mujer del Capitán D. Alonso Pereira de Moscoso, haciendo una donación a su hija Dña. Francisca Ozores Correa y Sotomayor.

- Copia de escritura de dote de Dña. María Juana de Araujo para casarse, otorgada en Nigrán el 28 de diciembre de 1606.

- Rel Provisión de 1655 del Capitán General de Galicia solicitada por Dña. Ángela Pereira de Moscoso.

«CUADERNOS DE ESTUDIOS GALLEGOS», Tomo XLVIII, Fascículo 114, Santiago 2001. 
- Reconocimiento de la piedra de la casa de la Torre hecha por Manuel Francisco de Nobas.

- Trueque entre D. Manuel Pereira y D. Francisco de Castro de Lira de todo el terreno que ocupan las casas resíos, etc., sacando el D. Francisco dentro de un año la piedra de las casas; la capilla de San Tomé de D. Manuel Pereira, es donde hoy tiene una D. Manuel Míguez, Presbitero».

De este fondo documental aquí resumido, podemos deducir un árbol genealógico de la casa de los Pereira de Nigrán, que en su día nos ocuparemos. Con referencia a esta del mayorazgo del Pazo de Arriba de Leirado encontramos a un D. Gonzalo de Castro del cual descienden D. Álvaro Gil de Castro y D. Pedro de Castro Ulloa, que c.c. Dña. Antonia Troncoso de Lira el 30 de Marzo de 1653, los cuales fundan este mayorazgo del Pazo de Arriba y t.p.h. a D. Fernando, bautizado el 21 de enero de 1657, quedando D. Francisco Antonio de Castro Troncoso de Lira y Sotomayor, como único heredero en 1687 el cual c.c. Dña. Benita Pallares Moscoso y t.p.h.a.:

- D. Fernando Manuel Moscoso y Lira.

- D. Rodrigo Antonio, baut. el 15-1-1693, en 1754 era patrono de la Capilla de Santo Tomás o San Tomé13.

- Dña. Benita Rosa de la Concepción, baut. el 22-4-1698».

Esta capilla de San Tomé o Santo Tomás, sin duda propia del Pazo de Arriba e inmediata al mismo, figura en el arreglo parroquial de 1854 como inútil y como sirviendo de abrigo a personas y ganados sin rastro de los que había sido, tal como se redacta en el mencionado arreglo.

\section{SAN ROQUE}

Inmediata a la Capilla de San Roque, en el cruce de carreteras de la parroquia de Leirado, en un lateral de un portalón encontramos el escudo (Fig. 14), muy rústico y de forma irregular representando las armas de los

\footnotetext{
${ }^{13}$ Fondo Curia, caxón 24, núm. 1. A.H.D. de Tui-Vigo.
} 


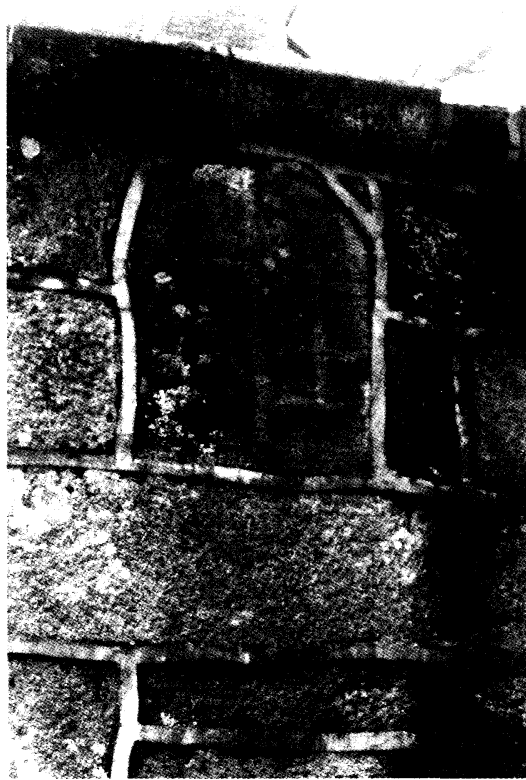

Fig. 14.

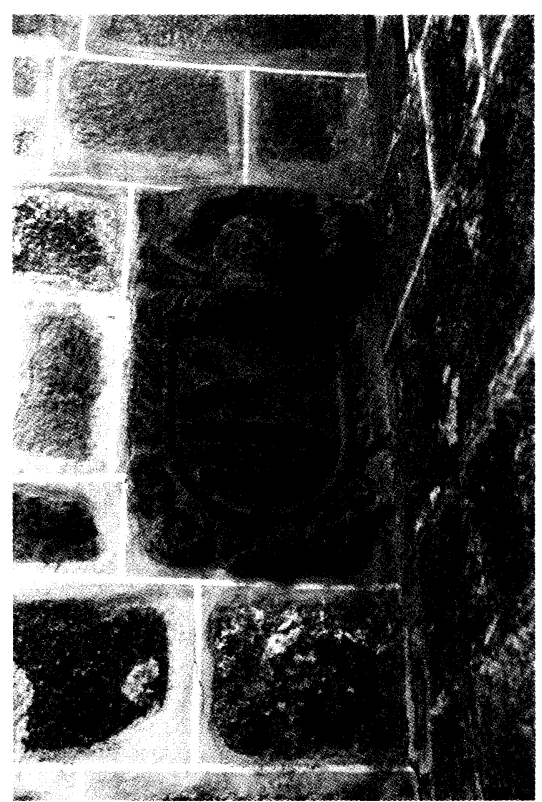

Fig. 15.

Pereira de Castro Ozores, ocupando la espada, que acompaña al león de la parte superior, toda la parte central del escudo. Esta casa debió pertenecer a la ya estudiada de Alcabra de Oleiros.

Relacionada con la misma vemos un foro de 1598 hecho por D. Gómez Correa Ozores de Sotomayor, Abad de Leirado, a Fernán Rodríguez y María Rodríguez, su mujer, de un pedazo de viña «blancella» en San Roque, y la dotación de 1604 hecha por el mismo D. Gómez Correa Ozores de la referida viña para reparos de la ermita de San Roque, que de nuevo había fundado y construido en su propio territorio ${ }^{14}$.

\section{IGLESIA DE SANTA MARÍA DE OLEIROS}

Tenemos constancia de la existencia de una capilla dedicada a San Mauro inclusa en esta iglesia parroquial de Oleiros, en cuyo muro exterior figura el escudo (Fig. 15), timbrado de un yelmo adornado con pena-

\footnotetext{
${ }^{14}$ Fondo Curia, caxón 32, núm. 3. A.H.D. de Tui-Vigo.
} 
chos y con orla floral. Ocupando el campo una cruz de San Andrés y tres fajas.

Según se indica en el Arrego Parroquial de 1854, fue fundada por el Capitán D. Ventura Avalle y Pereira del mayorazgo de Fiolledo, que en el citado año llevaba D. José María Avalle, cuyo vínculo había sido fundado por el Capitán D. Juan de Ojea c.c. Dña. Mariana de Avalle.

En 1826 se solicita una reducción de misas con que estaba dotada la capilla por D. Pedro Avalle Troncoso de Lira y Dña. Catalina de Barros Faxardo, su mujer ${ }^{15}$.

Con referencia a la cruz de S. Andrés del escudo que llevan los Arauxo portugueses, encontramos a un D. Manuel José de Avalle c.c. Dña. María de Araujo, vecinos de Oleiros ${ }^{16}$.

\footnotetext{
${ }^{15}$ Fondo Curia, Carpetas Nuevas. Oleiros. A.H.D. de Tui-Vigo.

${ }^{16}$ Véase nuestro trabajo, Heráldica de S. Paio de Fiolledo, en el Boletín núm. 19 de 1998. Seminario Fontán Sarmiento
}

«CUADERNOS DE ESTUDIOS GALLEGOS», Tomo XLVIII, Fascículo 114, Santiago 2001. 